\title{
Equilibrium and Kinetics Studies of adsorption of Copper (II) Ions on Natural Biosorbent
}

\author{
Rania Farouq and N. S. Yousef
}

\begin{abstract}
The Biosorption of Copper (II) ions from aqueous solution on natural biosorbent (Mussels) has been investigated. Batch shaking adsorption experiments were performed and equilibrium and kinetic isotherms were tested. Results show that Chitin can remove Copper (II) effectively from aqueous solution. To predict the adsorption isotherms and to determine the characteristic parameters for process design, eight isotherm models: Langmuir, Freundlich, Elovich, Temkin, Fowler-Guggenheim, Jovanovic, Koble-Corrigan, and Hill were applied to experimental data. The equilibrium data were analyzed. The results reveal that the adsorption isotherm models fitted the data in the order: Jovanovic $>$ Freundlich , Koble-Corrigan> Temkin> Fowler-Guggenheim> Elovich> Langmuir, Hill. Adsorption kinetic data were tested using pseudo-first order, pseudo-second order and Elovich model. The kinetics of the adsorption were found to fit the Elovich model.
\end{abstract}

Index Terms-Biosorption, chitin, copper (II), equilibrium and kinetic models.

\section{INTRODUCTION}

The continuously increasing demand for the commodities produced by chemical industries has triggered heavy metals accumulation in the eco system. [1]. Contamination of aquatic media by heavy metals is a serious environmental problem [2], [3]. Copper ions are mainly found in wastewaters of industries such as metal cleaning, plating baths, refineries, paper and pulp [4], fertilizers, tanneries, and wood preservatives. High concentration of copper causes enzyme inhibition leading to Wilson's diseases. It was estimated that the annual industrial discharges of copper into fresh water environments was $1.4 \times 10^{10} \mathrm{~g} / \mathrm{year}$, and the amount of copper in industrial wastes and sewage sludge that have been dumped into the ocean was $1.7 \times 10^{10} \mathrm{~g} / \mathrm{year}$ worldwide [5]. The world health organization (WHO) recommended a maximum acceptable concentration of copper in drinking water to be $1.5 \mathrm{mg} / \mathrm{l}$ [6]. Conventional metal removal techniques such as reverse osmosis, solvent extraction, lime coagulation and ion exchange methods [7], [8] are encountered with certain major disadvantages such as high energy requirements, incomplete removal and generation of large quantity of toxic waste sludge due to various reagents used in a series of treatments. Adsorption techniques are proved to be an effective and attractive process for removal of non-biodegradable pollutants [9], [10]

Manuscript received October 25, 2014, revised January 15, 2015.

The authors are with the Petrochemical Department, Faculty of Engineering, Pharos University, Canal El Mahmoudeya St. Semouha, Alexandria, Egypt (e-mail: rania_farouq29@yahoo.com, nohaysf@gmail.com, nohaysf@yahoo.com). from wastewater. Recently, the removal of metals, compounds and particulates from solution by biological material is recognized as an extension to adsorption and is named as biosorption [11]. Examples of biosorbents are [12], Algae [13], seaweeds [14] microorganisms [15], [16] and several biopolymers [17]. Chitin, which is the major component of carapaces, crusts and shells of crustaceans is the second most abundant organic resource next to cellulose on earth and the most abundant biopolymer in nature that is widely used for the adsorption of heavy metal ions [18], [19]. The present study aims to investigate the adsorption of copper (II) ions on river mussels shells obtained from local fish markets. Equilibrium data of adsorption studies were processed for the analysis of the adsorption equilibrium on the natural biosorbent.

\section{MATERIALS AND METHODS}

\section{A. Chemicals}

All reagents were of AR grade chemicals. A stock solution of copper was prepared in double distilled water using copper sulphate pentahydrate. All other solutions were prepared by diluting the stock solution. Copper ions concentrations were determined using atomic absorption spectrophotometer.

\section{B. Preparation of Biosorbent}

Mussels shells were collected locally from fish markets. They were washed efficiently with water after removing any entrained flesh, then were air dried and pulverized. The ground shells were screened on a set of screens into different size portions to be considered as chitin shells.

\section{Adsorption Experiments}

Batch adsorption experiments were carried out at the room temperature of $25^{\circ} \mathrm{C}$ in different conical flasks. Different weights of biosorbents (mussels shells) such as $(0.5,1,2,3$, $5 \mathrm{gms}$ ) were added to each flask. $25 \mathrm{ml}$ of $\mathrm{CuSO}_{4} \cdot 5 \mathrm{H}_{2} \mathrm{O}$ solution were added to each flask on the biosorbent. The mixture was shaken by a machine of shaker for a sufficient time to reach equilibrium. Then, the solution filtered and analyzed using atomic absorption spectrophotometer. The amount of copper adsorbed at equilibrium, qe $(\mathrm{mg} / \mathrm{g})$, was calculated by the following mass balance relationship:

$$
q_{e}=\left(C_{o}-C_{e}\right) * V / m
$$




\section{1) Langmuir isotherm}

The Langmuir adsorption isotherm [20], has been used to predict the performance of different biosorbents and is based on the assumption that uptake occurs on a homogenous surface by monolayer sorption with-out interaction between adsorbed molecules. The linear form of the Langmuir isotherm equation can be expressed as follows:

$$
\frac{1}{q_{e}}=\frac{1}{K_{L} \times q_{m}} * \frac{1}{C_{e}}+\frac{1}{q_{m}}
$$

From Fig. 1 the correlation coefficient $\left(R^{2}\right)$ equals 0.731 indicating an acceptable fit of the monolayer adsorption.

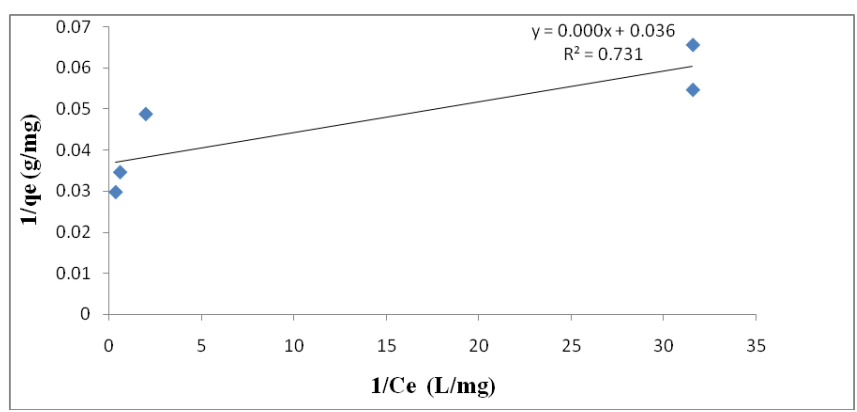

Fig. 1. Langmuir adsorption isotherm.

\section{2) Freundlich isotherm}

The Freundlich sorption isotherm [20], gives an expression encompassing the surface heterogeneity and the exponential distribution of active sites and their energies, and is expressed by the following equation:

$$
\log q_{e}=\log K_{F}+\frac{1}{n_{f}} \log C_{e}
$$

The values of $K_{F}$ and $n_{f}$ were calculated from the slope and intercept of the linear plot $\log q_{e}$ versus $\log C_{e}$ as shown in Fig. 2 and are reported in Table I. The value of the correlation coefficient $\left(R^{2}\right)$ was 0.879 , which is a higher value than that of Langmuir isotherm. Furthermore, if the value of $n_{f}$ lies between 1 and 10 , it indicates a favorable adsorption. The value of $n_{f}$ obtained was 7.040 indicating a favorable adsorption process.

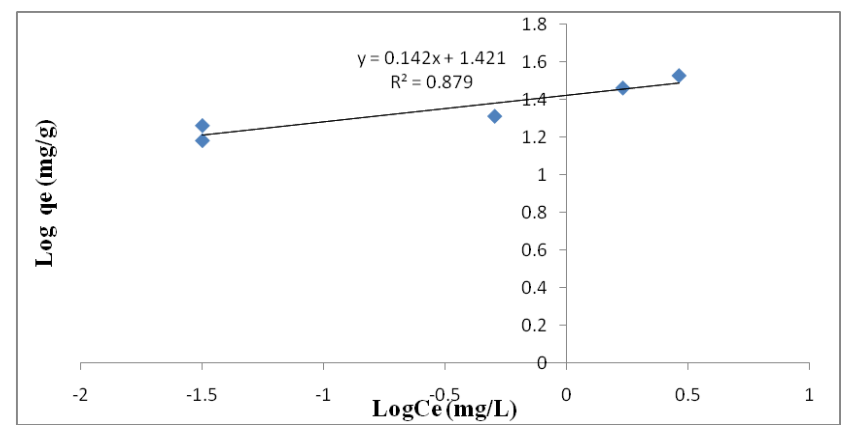

Fig. 2. Freundlich adsorption isotherm.

\section{3) Temkin isotherm}

The derivation of the Temkin isotherm assumes that the fall in the heat of sorption is linear rather than logarithmic, as implied in the Freundlich equation [20]. The heat of sorption of all the molecules in the layer would decrease linearly with coverage due to sorbate/sorbent interactions. The Temkin isotherm has generally been applied in the following form:

$$
q_{e}=B \ln A_{T}+B \ln C_{e}
$$

The constant $B$ is related to the heat of adsorption and $A$ is the equilibrium binding constant $(\mathrm{L} / \mathrm{mg})$ corresponding to the maximum binding energy. The plot of $q_{e}$ versus $\ln C_{e}$ enables the determination of $A_{T}$ and $B$ as shown in Fig. 3.

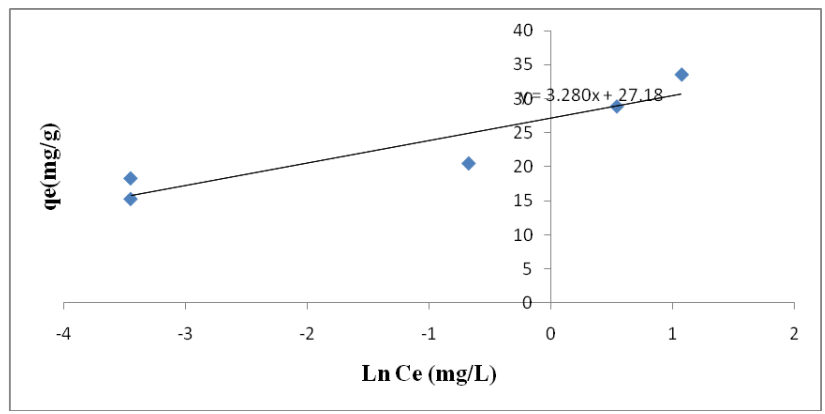

Fig. 3. Temkin adsorption isotherm.

\section{4) The Elovich isotherm}

The equation defining the Elovich [20] model is based on a kinetic principle assuming that the adsorption sites increase exponentially with adsorption, which implies a multilayer adsorption. It is expressed by the relation:

$$
\frac{q_{e}}{q_{m}}=K_{E} C_{e} e^{-\frac{q_{e}}{q_{m}}}
$$

If the adsorption obeys Elovich equation, Elovich maximum adsorption capacity and Elovich constant can be calculated from the slopes and the intercepts of the plot $\ln \left(q_{e} / C_{e}\right)$ versus $q_{e}$. As shown from Fig. 4, the value of the regression coefficient $R^{2}$ was 0.808 which is higher than that for Langmuir, therefore the adsorption of copper on chitin does fit the Elovich isotherm.

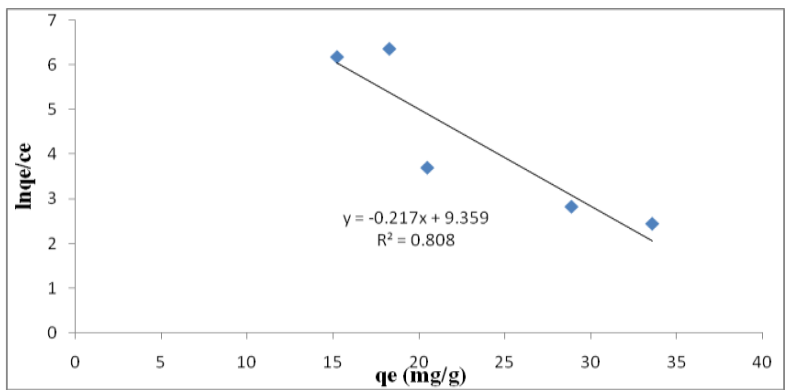

Fig. 4. Elovich adsorption isotherm.

\section{5) Fowler-Guggenheim isotherm}

Fowler-Guggenheim [21] derived an isotherm equation, it has the following explicit form:

$$
K_{F G} C_{e}=\frac{\theta}{1-\theta} e^{\frac{2 \theta W}{R T}}
$$


The heat of adsorption varies linearly with loading. If the interaction between the adsorbed molecules is attractive (that is $W$ is positive), the heat of adsorption will increase with loading and this is due to the increased interaction between adsorbed molecules as the loading increases. However, if the interaction among adsorbed molecules is repulsive (that is $W$ is negative), the heat of adsorption shows a decrease with loading. When there is no interaction between adsorbed molecules(that is $W=0$ ). As shown from Fig. 5, the value of the regression coefficient $R^{2}$ was 0.839 which is lower than that of Freundlich, and Temkin isotherms \& higher than Langmuir. The value of $W$ was -19590.4 , indicating repulsive interaction among adsorbed molecules, and showing a decrease of heat of adsorption with loading.

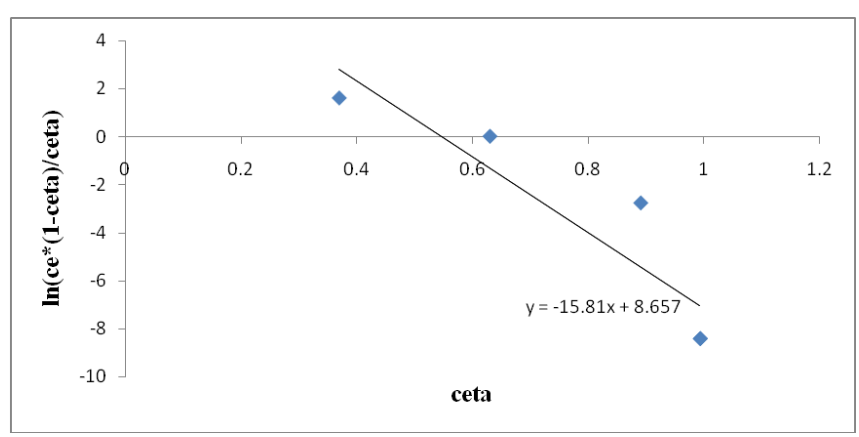

Fig. 5. Fowler-guggenheim adsorption isotherm.

TABLE I: ISOTHERM CONSTANTS OF TWO-PARAMETER MODELS FOR COPPER BIOSORPTION

\begin{tabular}{|c|c|c|c|}
\hline $\begin{array}{l}\text { Isotherm } \\
\text { model }\end{array}$ & Parameter & Value & $R^{2}$ \\
\hline Langmuir & $\begin{array}{l}K_{L} \\
q_{m}\end{array}$ & $\begin{array}{l}49.222 \\
27.119\end{array}$ & 0.7315 \\
\hline Freundlich & $\begin{array}{r}K_{f} \\
n_{f}\end{array}$ & $\begin{array}{l}4.144 \\
7.040\end{array}$ & 0.8796 \\
\hline Temkin & $\begin{array}{l}b_{T} \\
A\end{array}$ & $\begin{array}{c}755.186 \\
3969.224\end{array}$ & 0.8528 \\
\hline $\begin{array}{l}\text { Fowler-Gu } \\
\text { ggenheim }\end{array}$ & $\begin{array}{l}W \\
K_{F G}\end{array}$ & $\begin{array}{l}-19590.4 \\
-5752.99\end{array}$ & 0.8395 \\
\hline Elovich & $\begin{array}{l}q_{m} \\
K_{E}\end{array}$ & $\begin{array}{c}4.596 \\
2525.991\end{array}$ & 0.8082 \\
\hline Jovanovic & $\begin{array}{l}k_{j} \\
q_{m}\end{array}$ & $\begin{array}{c}-0.0876 \\
17.189\end{array}$ & 0.9212 \\
\hline
\end{tabular}

\section{6) The Jovanovic isotherm}

An adsorption surface assumption, considered in Jovanovic isotherm model [21] corresponds to another approximation for monolayer localized adsorption without lateral interactions. This model is similar to that of Langmuir model, except that the allowance is made in the former for the surface binding vibrations of an adsorbed species. This model is given by using the following nonlinear relationship:

$$
q_{e}=q_{m}\left(1-e^{K_{j} C_{e}}\right)
$$

As shown form Fig. 6 the value of the regression coefficient $R^{2}$ was 0.9212 , which is higher than all the other isotherm models.

The isotherm constants values of the two parameter models are shown in Table I.

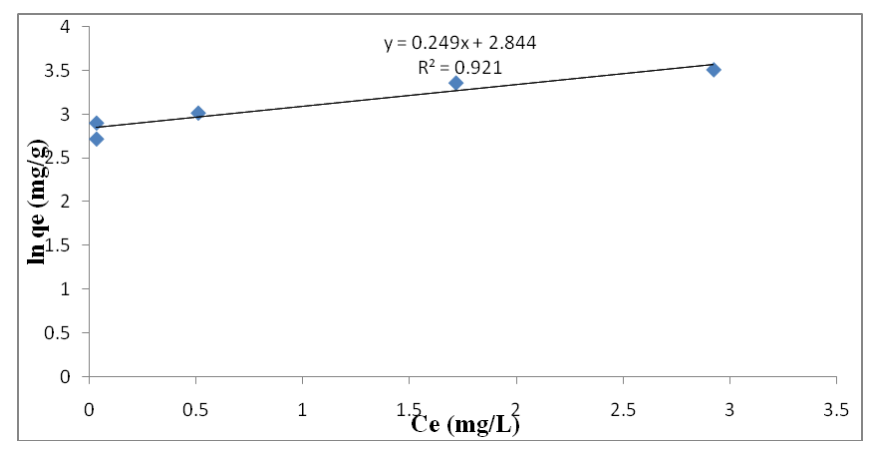

Fig. 6. Jovanovic adsorption isotherm.

\section{B. Three-Parameter Models}

\section{1) Hill isotherm}

Hill model [22], assumes that adsorption process as a cooperative phenomenon, with the ligand binding ability at one site on the macromolecule, may influence the different binding sites on the same macromolecule. It is described by the following equation:

$$
q_{e}=\frac{q_{s H} C_{e} n_{H}}{K D+C_{e} n_{H}}
$$

As seen from Fig. 7, the value of the regression coefficient $\mathrm{R}^{2}$ was 0.8795 which is higher than that of Langmuir.

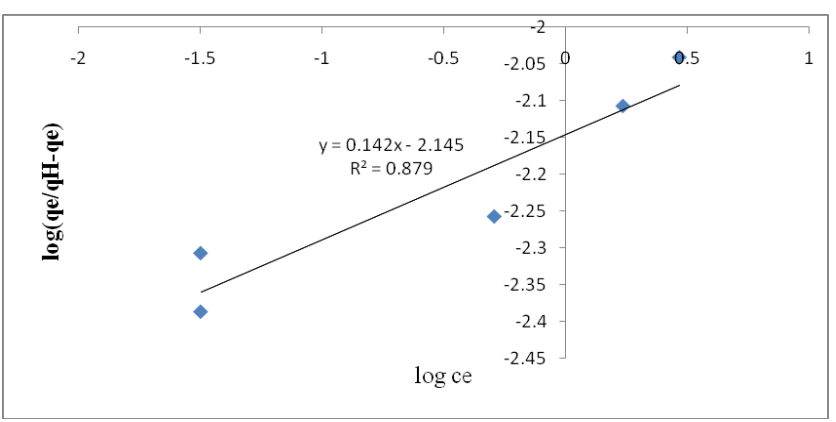

Fig. 7. Hill adsorption isotherm.

\section{2) Koble-Corrigan isotherm}

Koble-Corrigan model [22] is the three-parameter empirical model based on the combination of both the Langmuir and Freundlich isotherm equations represented in one non-linear equation of the equilibrium adsorption data. The model is commonly expressed by:

$$
q_{e}=\frac{a C_{e}^{n_{\mathrm{n}(\mathrm{K}-\mathrm{C})}}}{1+b C_{e}^{n_{\mathrm{n}(\mathrm{K}-\mathrm{C})}}}
$$

This model is generally applied for heterogeneous sorbent surfaces.

As shown in Fig. 8, the value of the regression coefficient $R^{2}$ was 0.780 which is higher than that of Langmuir isotherm.

The isotherm constants values of the three parameter models are shown in Table II. 


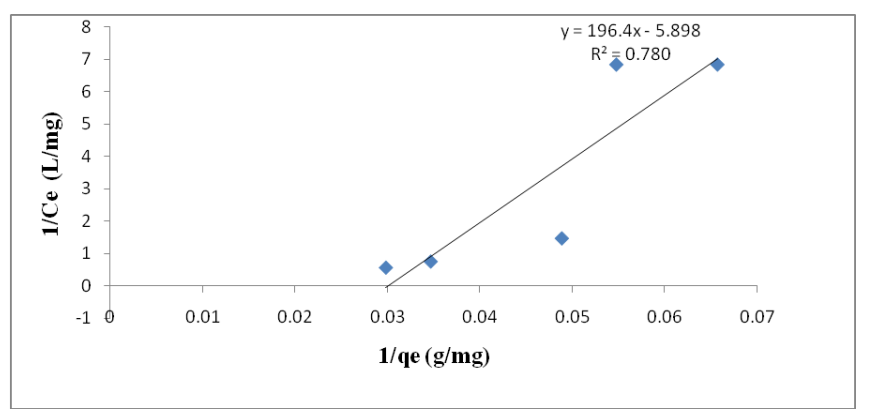

Fig. 8. Hill adsorption isotherm.

TABLE II: ISOTHERM CONSTANTS OF THREE-PARAMETER MODELS FOR COPPER BIOSORPTION

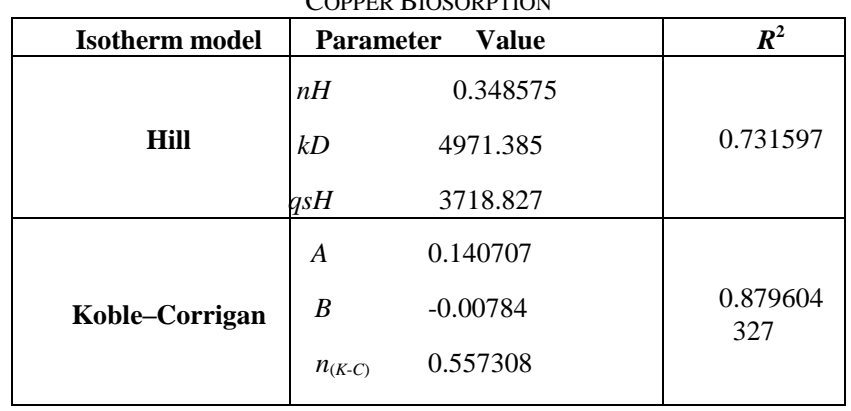

\section{ADSORPTION KINETICS}

Different kinetic models including pseudo-first-order, pseudo-second-order and Elovich model were tested.

\section{A. The Pseudo-First-Order Model}

The Lagergren's rate equation [23] is one of the most widely used rate equation to describe the adsorption of an adsorbate from the liquid phase. The linear form of pseudo-first-order equation is given as:

$$
\log \left(q_{e}-q_{t}\right)=\log q_{e}-\frac{k_{1}}{2.303} t
$$

The experimental results of the first order rate constants are presented in Fig. 9. The adsorption data have a low regression coefficient which suggests that the adsorption of copper on biosorbent does not follows the pseudo-first order adsorption kinetics.

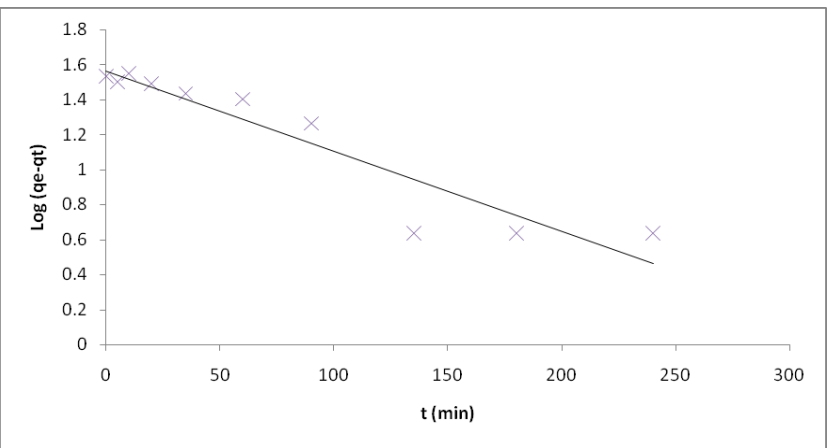

Fig. 9. First order reversible reaction kinetics plot for the adsorption of $\mathrm{Cu}$.

\section{B. The Pseudo-Second-Order Rate Equation}

The pseudo-second order kinetic model is based on the assumption that chemisorption is the rate determining step and is given as [23]:

$$
\frac{t}{q_{t}}=\frac{1}{k_{2} q_{e}{ }^{2}}+\frac{1}{q_{e}}
$$

The obtained data did not show a good compliance with the pseudo second-order equation. The correlation coefficient for the linear plot, $R^{2}$, suggests a poor relationship between the parameters and also explained that the process of adsorption do not fit pseudo second-order kinetic model (Fig. 10).

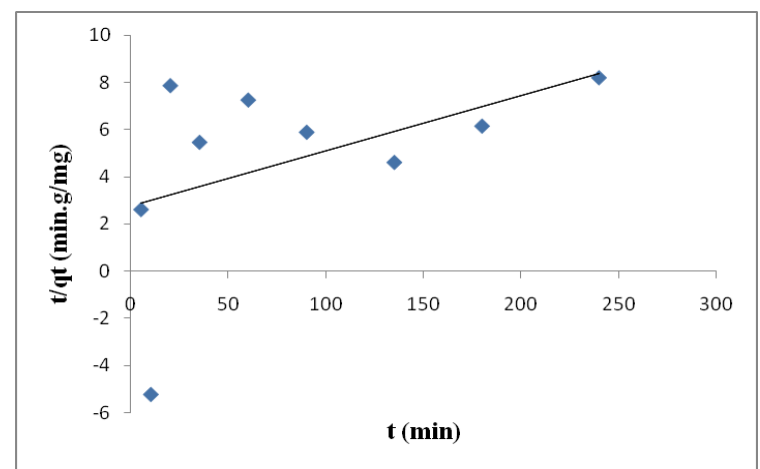

Fig. 10. Second order reversible reaction kinetics plot for the adsorption of $\mathrm{Cu}$.

\section{Elovich Model}

The Elovich equation was first developed to describe the kinetics of chemisorptions of gas onto solids [23]. The linear form of the Elovich model is presented by the following equation:

$$
q_{t}=\frac{1}{\beta} \ln (\alpha \beta)+\frac{1}{\beta} \ln (t)
$$

The constants $\alpha$ and $\beta$ were obtained from the slope and intercept of the linear plot of $q_{t}$ versus $\ln t$ as shown in Fig. 11 and the values were presented in Table III. From Table III, the correlation coefficient of $\mathrm{Cu}^{2+}$ was 0.8595 which is better than that of both the pseudo- first and second order models.

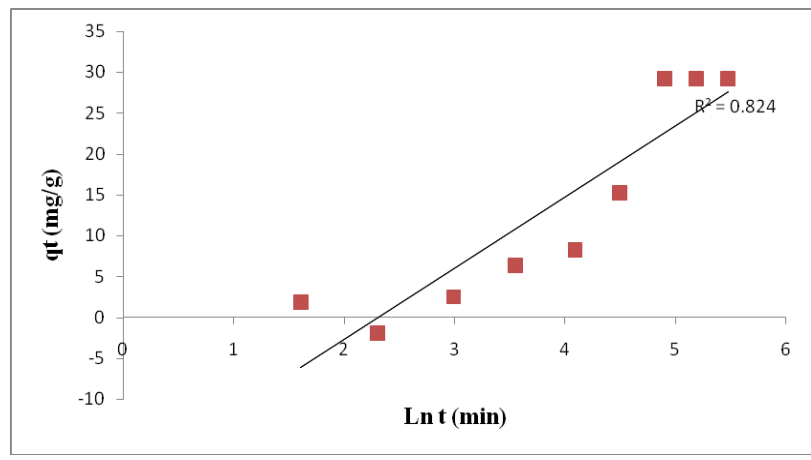

Fig. 11. Elovich kinetics plot for the adsorption of $\mathrm{Cu}$.

TABLE III: ADSORPTION KINETICS MODELS

\begin{tabular}{|c|cc|c|}
\hline Isotherm model & Parameter & Value & $\boldsymbol{R}^{\mathbf{2}}$ \\
\hline $\begin{array}{c}\text { Pseudo-first- order } \\
\text { equation }\end{array}$ & $k_{1}$ & $\begin{array}{c}0.002964 \\
\text { qcalc }\end{array}$ & 0.6803 \\
\hline $\begin{array}{c}\text { Pseudo-second- } \\
\text { order equation }\end{array}$ & $\begin{array}{c}k_{2} \\
\text { qcalc }\end{array}$ & $\begin{array}{c}2.74 \\
0.363784\end{array}$ & 0.221 \\
\hline Elovich equation & $\alpha$ & 0.859516 & 0.824 \\
\hline
\end{tabular}




\section{CONCLUSIONS}

A biosorbent made of Mussels was successfully utilized for the removal of copper ions from aqueous solution by batch adsorption method.

The equilibrium data were tested using the Langmuir, Freundlich, Temkin, Elovich, Fowler-Guggenheim, Jovanovic, Hill, and Koble-Corrigan isotherms. Correlation coefficients and Error analysis indicated the following order to fit isotherms Jovanovic > Freundlich ,Koble-Corrigan> Temkin> Fowler-Guggenheim> Elovich> Langmuir, Hill. Kinetic parameters were also analyzed using the pseudo-first order, Pseudo-second order, and Elovich model. Kinetic studies showed that the adsorption of copper ions onto chitin followed Elovich kinetic model.

\section{LIST OF SYMBOLS}

Symbol Description:

$a$ : Koble-Corrigan parameter

$A_{T}$ : Temkin isotherm equilibrium bindingconstant

$B$ : Koble-Corrigan parameter

$b t$ : Temkin isotherm

$B$ : Heat of sorption constant $J / \mathrm{mol}$

$C_{o}$ : initial copper concentration $\mathrm{g} / \mathrm{L}$

$C_{e}$ : Equilibrium copper concentration $\mathrm{g} / \mathrm{L}$

$k_{1}$ : Rate constant of the pseudo-first-order $\min ^{-1}$

$k_{2}$ : Rate constant of the pseudo-second-order g/mg.min

$k_{n}$ : Constant of complex formation between adsorbed molecules

$K_{D}$ : Hill constant

$K_{E}$ : Elovich equilibrium constant $\mathrm{L} / \mathrm{mg}$

$K_{F}$ : Freundlich adsorption capacity constant $(\mathrm{mg} / \mathrm{g})$ $(\mathrm{mg} / \mathrm{L})^{1 / n}$

$K_{F G}$ : Fowler-Guggenheim equilibrium constant $\mathrm{L} / \mathrm{mg}$

$K_{1 H}$ : Hill-de Boer constant L/mg

$K j$ : Jovanovic isotherm constant $\mathrm{L} / \mathrm{mg}$

$K_{2}$ : Energetic constant of the interaction between adsorbed molecules $\mathrm{J} / \mathrm{mol}$

$K_{L}$ : Langmuir isotherm constant $\mathrm{L} / \mathrm{mg}$

$m$ : Mass of adsorbent $\mathrm{g}$

$n_{f}$ : Freundlich adsorption intensity constant

$n_{H}$ : Hill cooperativity coefficient of the binding interaction

$n_{(K-C)}$ : Koble-Corrigan parameter

$q_{e}:$ amount of copper adsorbed at equilibrium $\mathrm{mg} / \mathrm{g}$

$q_{e, i, c a l}$ : amount of calculated adsorbed copper at equilibrium $\mathrm{mg} / \mathrm{g}$

$q_{\text {mmaximum }}:$ monolayer adsorption capacity $\mathrm{mg} / \mathrm{g}$

$q_{S H}$ : Hill isotherm maximum uptake saturation $\mathrm{mg} / \mathrm{L}$

$q_{t}$ : amount of copper adsorbed at time $(t) \mathrm{mg} / \mathrm{g}$

$R$ : Universal gas constant $\mathrm{J} / \mathrm{mol}$. $K$

$T$ : Temperature $K$

$V$ : Volume of solution $\mathrm{L}$

$W$ : Interaction energy between adsorbed molecules $K J / \mathrm{mol}$

Greek:

$\alpha$ : initial sorption rate constant $\mathrm{mg} / \mathrm{g}$ min

$\beta$ : extent of surface coverage and activation energy for chemisorptions $\mathrm{g} / \mathrm{mg}$

$\theta$ : degree of surface coverage of adsorbent surface
$\theta_{H}$ : fractional coverage.

\section{REFERENCES}

[1] P. N. Sudha, Chitin, Chitosan, Oligosaccharides and Their Derivatives, Ed. SeKwon Kim: CRC Press, 2010, pp. 561-585.

[2] A. Baraka, P. Hall, and J. J. Heslop, "Melamine-formaldehyde-NTA chelating gel resin, synthesis, characterization and application for copper (II) ion removal from synthetic waste water," J. Hazard. Mater, vol. 140, pp. 86-94, 2007.

[3] M. Parmar and L. S. Thakur, "Heavy metal $\mathrm{Cu}, \mathrm{Ni}$ and $\mathrm{Zn}$ : Toxicity, health hazards and their removal techniques by low cost adsorbents: A short overview," Int. J. Plant. Anim. Environ. Sci, vol. 3, no. 3, pp. 143-157, 2013.

[4] M. W. Wan, C. C. Wang, and C. M. Chen, "The adsorption study of copper removal by chitosan-coated sludge derived from water treatment plant," Int. J. Environ. Sci. Technol, vol. 4, no. 5, pp. 445-451, 2013.

[5] J. O. Nriago, Copper in the Environment Part I: Ecological Cycling, New York: John Wiley \& Sons, 1979, pp. 1-171.

[6] C. S. Rao, Environmental Pollution Control Engineering, New Delhi: Wiley Eastern, 1992.

[7] Z. B. Alfassi, Pre-Concentration Techniques for Trace Elements, Boston: CRC Press, 1992

[8] H. F. Walton and R. D. Rocklin, Ion Exchange in Analytical Chemistry, Boston: CRC Press, 1990, ch. 9.

[9] I. Nhapi, N. Banadda, R. Murenzi, C. B. Sekomo, and U. G. Wali, "Removal of heavy metals from industrial wastewater using rice husks," Open. Environ. Eng. J., vol. 4, pp. 170-180, 2011

[10] C. Saka, O. Sahin, and M. M. Kucuk, "Applications on agricultural and forest waste adsorbents for the removal of lead (II) from contaminated waters," Int. J. Environ. Sci. Technol, vol. 9, pp. 379-394, 2012.

[11] S. Mandina, F. Chigondo, M. Shumba, B. C. Nyamunda, and E. Sebata, "Removal of chromium (VI) from aqueous solution using chemically modified orange (citrus cinensis) peel," J. Appl. Chem, vol. 6, no. 2, pp. 66-75, 2013

[12] S. B. Imandi, R. Chinthala, S. Saka, R. R. Vechalapu, and K. K. Nalla, "Optimization of chromium biosorption in aqueous solution by marine yeast biomass of Yarrowia lipolytica using Doehlert experimental design," Af. J. Biotechnol, vol. 13, no. 12, pp. 1413-1422, 2014.

[13] V. K. Gupta, A. K. Shrivastava, and N. Jain, "Biosorption of chromium(VI) from aqueous solution by green algae Spirogyra species," Water Resour, vol. 35, pp. 4079-4085, 2001.

[14] R. Elangovan, L. Philip, and K. Chandraraj, "Biosorption of chromium species by aquatic weeds: Kinetics and mechanism studies," J. Hazard. Mater, vol. 152, pp. 100-112, 2008.

[15] Y. Sahin and A. Ozturk, "Biosorption of chromium (VI) ions from aqueous solution by the bacterium Bacillus thuringiensis," Process Biochem, vol. 40, pp. 1895-1901, 2005.

[16] T. Fan, Y. Liu, B. Feng, G. Zeng, C. Yang, M. Zhou, H. Zhou, Z. Tan, and X. Wang, "Biosorption of cadmium (II), Zinc (II) and lead (II) by penicilliumsimplicissimum: Isotherms, kinetics and thermodynamics," J. Hazard. Mater, vol. 160, pp. 655-661, 2008

[17] Y. Wu, S. Zhang, X. Guo, and H. Huang, "Adsorption of chromium (III) on lignin," Bioresour Technol, vol. 99, pp. 7709-7715, 2008.

[18] K. H. Chu and M. A. Hashim, "Adsorption and desorption characteristics of zinc on ash particles derived from oil palm waste," $J$. Chem Technol Biotechnol, vol. 77, no. 6, pp. 685-693, 2002.

[19] R. Kumar, "A review of chitin and chitosan applications," React. Funct. Polym. P., 2000.

[20] O. Hamdaouia and E. Naffrechoux, "Modeling of adsorption isotherms of phenol and chlorophenols onto granular activated carbon Part I. Two-parameter models and equations allowing determination of thermodynamic parameters," J. Hazard. Mater, vol. 147, pp. 381-394, 2007.

[21] S. Rangabhashiyam, N. Anu, M. S. GiriNandagopal, and N. Selvaraju, "Relevance of isotherm models in biosorption of pollutants by agricultural by products," J. Environ. Chem. Eng., pp. 2398-2414, 2014.

[22] K. Y. Foo and B. H. Hameed, "Insights into the modeling of adsorption isotherm systems," Chem. Eng. J., vol. 156, pp. 2-10, 2010.

[23] P. S. Kumara, S. Ramalingamb, S. D. Kiruphac, A. Murugesanc, T. Vidhyadevic, and S. Sivanesan, "Adsorption behavior of nickel (II) onto cashew nut shell: Equilibrium, thermodynamics, kinetics, mechanism and process design," Chem. Eng. J., vol. 167, pp. 122-131, 2011. 


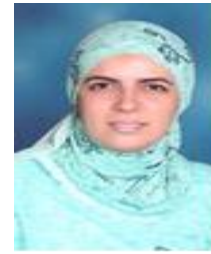

Rania Farouq was born in Alexandria Egypt, on September 29, 1981. She received her PhD degree in chemical engineering in 2013 with a CGPA (A-) from the Faculty of Engineering, Alexandria University in Egypt. She got her master of science in chemical engineering was in 2009 with a CGPA (B+) from Faculty of Engineering, Alexandria University in Egypt. And she received her diploma in chemical engineering in 2006 with general grade good. She obtained her bachelor of science in chemical engineering in 2003.

Rania Farouq is a lecturer in Pharos University in Alexandria in Egypt-Petrochemical Engineering Department.

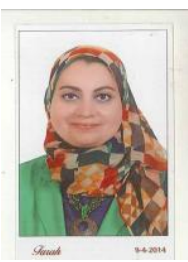

N. S. Yousef was born in Alexandria Egypt, on June 5,1980 . She received $\mathrm{PhD}$ in chemical engineering in 2011 from Faculty of Engineering, Alexandria University in Egypt. Master of science in chemical engineering, in 2007 from Faculty of Engineering, Alexandria University in Egypt. B.Sc. in Chemical Engineering from Alexandria University in Egypt in June 2002.

N. S. Yousef is a lecturer in Pharos University in Alexandria in EgyptPetrochemical Engineering Department. 